\title{
ESTUDO PARA CONSTRUÇÃO DE METODOLOGIA DE DESIGN DE MODA SUSTENTÁVEL
}

\author{
Evelise Anicet Rüthschilling \\ NDS- PGDesign/ UFRGS \\ anicet@ufrgs.br \\ Anne Anicet \\ UNIRITTER \\ anne anicet@uniritter.edu.br
}

\begin{abstract}
Resumo: Este texto descreve resultados de pesquisa e sugere um modelo de metodologia projetual para o design de moda sustentável com vistas à fabricação em baixa escala produtiva. Analisa o cenário e atores da cadeia produtiva e identifica o designer como elemento-chave para promover a mudança de um fazer tradicional para novos modos de criação e produção de roupas alinhados às estratégias de desenvolvimento sustentável. Considerando incipiente a produção científica nesta área e escassas as publicações, este trabalho visa apoiar o trabalho de alunos, professores e profissionais de design de moda no desenvolvimento de seus projetos, assim como também compartilhar resultados de investigação científica baseada na observação participante e levantamento bibliográfico.
\end{abstract}

Palavras-chave: metodologia, design de moda, design para sustentabilidade.

Abstract: This paper describes research results and suggests a model of design methodology for the sustainable fashion design with a view to manufacturing in low production scale. Analyzes the scene and actors of the production chain and identifies the designer as a key element to promote the change from the traditional way to make to new methods of creation and production of clothing aligned with sustainable development strategies. Considering incipient the scientific production in this area, and few publications, this work aims to support the work of students, teachers and 
professionals of fashion design in the development of their projects, as well as to share the results of scientific research based on participant observation and bibliographic .

Keywords: methodology, fashion design, design for sustainability.

\section{INTRODUÇÃO}

Este texto busca compartilhar com colegas os achados de pesquisa recente sobre possível metodologia em design de moda inserindo o comprometimento com os pressupostos sustentáveis.

O trabalho se constitui tecendo conhecimentos construídos pelas autoras nas áreas teórica e prática do design de moda e sustentabilidade, mediados pela contribuição teórica de vários autores, principalmente de Alison Gwilt (2011) ${ }^{1}$, que é professora pesquisadora inglesa sobre sustentabilidade aplicada à moda e têxteis que nos brinda com reflexão sobre como produzir moda sustentável.

A pesquisa utilizou métodos de coleta de dados através de observação participante e levantamento bibliográfico.

O texto parte do problema de estruturar uma metodologia de design de moda para sustentabilidade para apoiar o trabalho de alunos, professores e profissionais da área comprometidos com a causa ecológica.

A partir da constatação de que a indústria têxtil e de confecção são muito poluentes, é analisado o cenário onde são feitos esforços para minimizar o estado de degradação ambiental.

O foco está na função do designer e a necessidade de se informar e se instrumentalizar para projetar tentando "despoluir os sistemas" (VEZZOLI, p. 23, 2012). Dessa forma, são estudadas estratégias de intervenção que estão ao alcance do profissional de moda, ou seja, a de projetar produtos e serviços a serem executados através de processos limpos e planejar seus usos e maneiras de descarte para que sejam menos poluentes.

\section{DESENVOLVIMENTO}

A produção contemporânea de roupas continua alavancada pela demanda de atingir as expectativas da empresa, com restrições de orçamentos, recursos disponíveis de manufatura, fatores da marca e objetivo de lucros, principalmente. As necessidades do usuário vêm em segundo lugar e os fatores ecológicos por último. Nesse cenário, Gwilt (2011) aponta para a tendência de ser muito mais difícil a mudança em empresas de grande escala que em micro, pequenas e médias empresas.

${ }^{1}$ Texto analisado: Producing sustainable fashion: the points for positive intervention by the fashion designer do livro Shaping Sustainable Fashion: changing the way we make and use clothes, Gwilt \& Rissanen, Earthscan: London, 2011. 
Os grandes sistemas produtivos de artigos de moda e principalmente de vestuário tendem a simplesmente seguirem o que a empresa sempre fez: a estética característica da marca já identificada pelo consumidor e projetar contando apenas com os equipamentos e recursos humanos que a empresa possui que são padrões de design e produção já formatados. As pesquisas (RUTHSCHILLING, 2012) mostram que os designers inseridos nesse sistema também apresentam resistência à mudança. Talvez por comodidade, talvez por medo de mudar, por falta de vontade de seus superiores etc.. Normalmente se verifica também como entraves à mudança e inovação a falta de estrutura organizacional ou de conscientização dos donos de empresa e funcionários. Essa inércia se propaga também pelos players da cadeia: os representantes, os compradores, vendedores etc. Normalmente, nesses casos, a equipe comercial possui grande poder de decisão, comandando o trabalho da equipe criativa.

Entretanto, enquanto as roupas seguem sendo projetadas a partir de dados econômicos, se torna fundamental que se possa medir e minimizar o impacto disso sobre a sociedade e o ambiente (GWILT, 2011).

Vezzoli (2012) sintetiza a opinião de vários pesquisadores, afirmando que a mudança de padrões tradicionais de projetação surge atrelada à inovação: "a obtenção de um potencial mais significativo, para se atuar, com objetivos de promover mudanças radicais para um consumo sustentável, parece se localizar no aumento das possibilidades de inovação,..." (Vezzoli, p.25, 2012). O autor se refere a uma inovação que envolve os atores da cadeia produtiva em questão, ou seja, o designer, o fabricante, os fornecedores, comerciantes, dentre outros, e aponta para sistemas de produto-serviço (PSS).

$\mathrm{Na}$ área de moda, os sistemas produtivos e cadeias de serviços são muito complexos. Para facilitar este estudo, optou-se por isolar a variável de serviço, debruçando-se somente sobre o projeto de produto de moda.

\subsection{A Moda compreendendo a sustentabilidade}

A análise feita em livros, revistas de moda, jornais e demais meios de comunicação em mídias eletrônicas mostram que a maioria das modas ditas "sustentáveis" não desenvolve roupas realizadas no processo tradicional apenas com aparência sustentável caracterizada por elementos visuais estandardizadas como "Green" (KAWAMURA, 2005).

Autores como Fuad-Luke $(2004,2010)$ e Gwilt (p. 67, 2011) compartilham desta ideia e se referem a isso como roupas de "inspiração" eco ou verde e que estão cada vez mais usuais nas reportagens em revistas populares de moda, mas que não parecem estar comprometidos realmente com pressupostos éticos, sociais e ambientais.

Por outro lado, é preciso considerar que estamos exigindo algo do designer que a maioria dos profissionais também não domina. Na verdade, nem o designer de moda, nem o jornalista, nem o consumidor têm oportunidade de receber educação e aprender os critérios de sustentabilidade de forma mais consistente, mesmo por que 
esses critérios ainda não estão bem estruturados na sociedade em geral, que dirá em relação à moda.

Para auxiliar nessa abordagem superficial e fragmentada em que os conceitos são passados aos poucos para o senso comum, e encorajar o designer, Gwilt (2011) diz que deve haver a apreciação de três chaves iniciais de solução de problemas da área. $\mathrm{Na}$ primeira a autora sugere introduzir o assunto aos designers práticos primeiro ajudando o aluno, professor ou profissional a entender a sustentabilidade e suas estratégias; quais são elas e como podem se integrar ao sistema de fazer roupa. A segunda ação seria o esforço de integração de métodos pessoais de criação e desenvolvimento de projeto. A terceira seria incorporar o DNA sustentável já no briefing. A importância disso recai no fato de que a maioria dos designers de moda não costuma trabalhar a partir de briefing bem formulado. Trabalham de forma mais empírica.

\subsection{0 papel do designer de moda}

$\mathrm{Na}$ indústria de confecção de larga escala, as etapas de produção se dão de forma vertical e são operadas por grande número de colaboradores, de forma que cada fase envolve pessoas diferentes que normalmente trabalham separadamente, em locais e tempos diferentes.

Nesse modelo de sistema produtivo, o designer fica isolado na fase de criação e quase excluído de oportunidade de interação com os outros contribuidores-chave no processo produtivo e comercial. Ou seja, no sistema vertical ou linear de produção há a separação entre quem projeta e quem executa. $O$ fato de que nenhum setor tem a visão do todo é uma fragilidade de nossa sociedade tecnológica (GWILT, 2011).

Por outro lado, fora do reino da grande escala, existem as micro-empresas que, no campo da moda, normalmente são constituídas pelo próprio designer com alguns auxiliares, que se ocupam da pesquisa e desenvolvimento das coleções e a produção é feita fora da empresa, sendo o serviço terceirizado por outras empresas. De forma progressiva, isso também acontece com pequenas e médias empresas, que vão aumentando o número de colaboradores e a produção, mas essa classificação depende de cada país e tem mais a ver com o montante financeiro de faturamento para fins de cobrança de impostos do que o número de pessoas envolvidas.

Vale considerar que este é o panorama atual brasileiro, uma vez que as grandes empresas estão se fragmentando em função da tendência de deslocamento de parcela significativa da produção para países emergentes, na busca por redução de custos (Cenário Vestuário, SEBRAE, 2012). Percebe-se também que os profissionais afastados da indústria da moda e enfrentando falta de empregos estão se deslocando para o setor acadêmico, para atuarem como professores ou técnicos de ateliês de corte e costura. Nesse cenário, observa-se também que o Brasil já possui mais do que quatrocentos cursos de moda que formam estilistas ou designers de moda. Sendo 
assim, a maioria dos egressos desses cursos tende a abrir sua própria microempresa de moda.

Cabe, então, estudar o papel do designer nessas empresas. Como membro central da equipe é responsável desde as primeiras idéias até o controle de qualidade dos primeiros exemplares liberados para venda. Atua e/ou influencia em todos os setores: pesquisas de inspirações e de mercado, projeto e edição de coleções, seleção de materiais, tecidos, aviamentos, acompanhamento de confecção de moldes e modelagem, custos, produção de pilotagem, mostruário, comunicação, ponto de venda etc.. (KAWAMURA, 2005) Verifica-se a tendência de que a influência do designer acompanhe todas as fases de design e de produção quanto menor for a empresa.

Percebe-se aí uma grande oportunidade para intervenções positivas do designer em termos de sustentabilidade nas micro, pequenas e médias empresas. Mas como pode o designer garantir que o produto que ele criou atinge os critérios de mercado e objetivos de sustentabilidade ao mesmo tempo? (GWILT, 2011).

\subsection{A intervenção do designer de moda}

O designer de moda que pretende projetar considerando o ciclo de vida do produto deve assimilar primeiro todos os atributos semânticos da marca para qual está projetando, quer sejam de estilo, imagem no mercado, perfil do consumidor, além dos atributos técnicos como capacidade produtiva, forças e fraquezas.

Um segundo aspecto é o que diz respeito ao projeto propriamente dito, definir quais serão os elementos de design usados na coleção: linha, forma, proporção, cores, materiais, recursos de diferenciação no mercado, tratamentos de superfície, temas, tendências contemporâneas, mercado, público-alvo e gêneros de moda. A questão é como definir e inserir os critérios de sustentabilidade no processo de desenvolvimento de um novo produto?

Como um caminho inicial, Gwilt (2011, p.61) retoma as cinco fases principais do processo criativo e produtivo em sistema tradicional de fabricação de artefatos de moda para propor reflexão ao designer sobre a integração com a sustentabilidade. 0 objetivo é fomentar uma mudança gradual e auxiliar na sensibilização do designer, sua equipe e demais atores do processo de fabricação. Conforme mostra a Figura 1, as cinco fases são: pesquisa e análise, fase de síntese, fase de seleção, fase de manufatura e fase de distribuição.

A questão que se coloca, e já apreciada anteriormente, é o problema que normalmente os designers de moda trabalham de forma instintiva e não tomam total consciência sobre os critérios que vão conduzi-lo no caminho seguro de refinamento de cada projeto individual de roupa, no conjunto da coleção. O briefing deve incluir informações e ideias de desenvolvimento que se encontrem com os objetivos da empresa e as necessidades dos clientes (psicológicas, físicas, financeiras, sociais etc.), além de serem passíveis de serem postas em produção, considerando limitações técnicas, tecnológicas, de recursos humanos e de orçamento. 


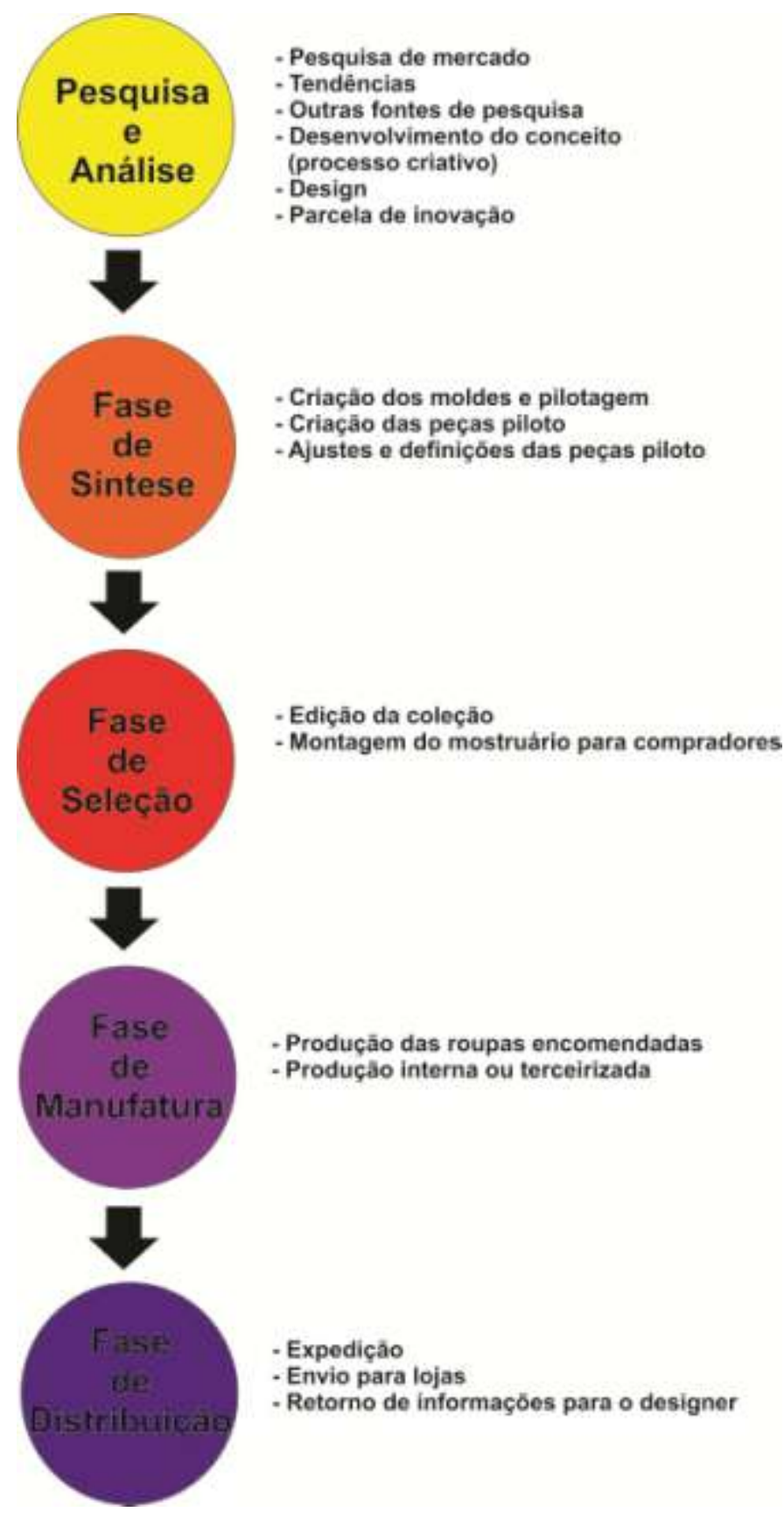

FIGURA 1: Fases de metodologia criativa e produtiva em design de moda tradicional. FONTE: Adaptação das autoras a partir de GWILT, 2011, pg.61 apud SINHA, 2002.

Gwilt (2011) sugere que em cada etapa sejam redefinidas as ações, num esforço de alinhar os processos produtivos da empresa com possíveis estratégias sustentáveis. Esse é o primeiro passo para ir alterando a seqüência de atividades que tipicamente ocorre na indústria da moda, já descrita por muitos autores contemporâneos como (RECH, 2002; SORGER \& UDALE, 2008; TREPTOW, 2003; FLETCHER \& GROOSE, 2011). 
Percebe-se aí uma grande oportunidade para intervenções positivas do designer que, via inovação, pode inserir a sustentabilidade nas microempresas, pequenas e médias empresas.

\subsection{Uma nova metodologia para a moda}

Os atores do sistema produtivo de moda, coordenados pelo designer, quando atingem o estado de atenção às causas sustentáveis podem propor avanço para que as intervenções sejam mais efetivas. Nesse sentido, propõe-se um novo esquema para apoiar o projeto em design de moda de micro, pequena e média escalas de produção, baseado no quadro delineado por Gwilt $(p .68,2011)$ para alta moda.

O gráfico proposto pela autora propõe uma metodologia de projetação para design de moda sustentável com as respectivas fases de design e de produção em roupas sob medida, levando em consideração as estratégias sustentáveis abordadas ao longo do ciclo de vida do produto.

De acordo com Manzini e Vezzoli (2008, p.91), o ciclo de vida do produto pode ser definido como um conjunto de atividades e processos, no qual cada um deles absorve certa quantidade de energia, resultando numa série de transformações e liberando emissões de naturezas diversas. Para os autores as etapas do ciclo de vida do produto são: pré-produção, produção, distribuição, uso e eliminação.

A análise do ciclo de vida do produto proposto por Manzini e Vezzoli (2008) juntamente com a metodologia de design e processo proposta por Gwilt (2011) aliadas às experiências das autoras do presente artigo, resultou na metodologia de projetação para design de moda sustentável para baixa escala de produção (Figura 2).

Conforme proposto no novo esquema, a fase de design e as fases de produção em baixa escala possuem um movimento cíclico e contínuo nas quais devem ser observadas as estratégias sustentáveis que permeiam cada etapa. As fases de design e produção são: selecionando materiais, interagindo com artesãos, produção, informação interagindo com o consumidor, ferramentas online de participação do cliente, cuidados pós-venda e descarte do vestuário.

Em cada fase deve-se observar a incorporação das diretrizes sustentáveis com o intuito de desenvolver produtos mais ecofriendly. Dentre as estratégias estão: design para o bem estar social, design para minimizar o desperdício, design para a desaceleração do consumo, design para participação do usuário, design para sistema de produto-serviço e design para desmontagem. 


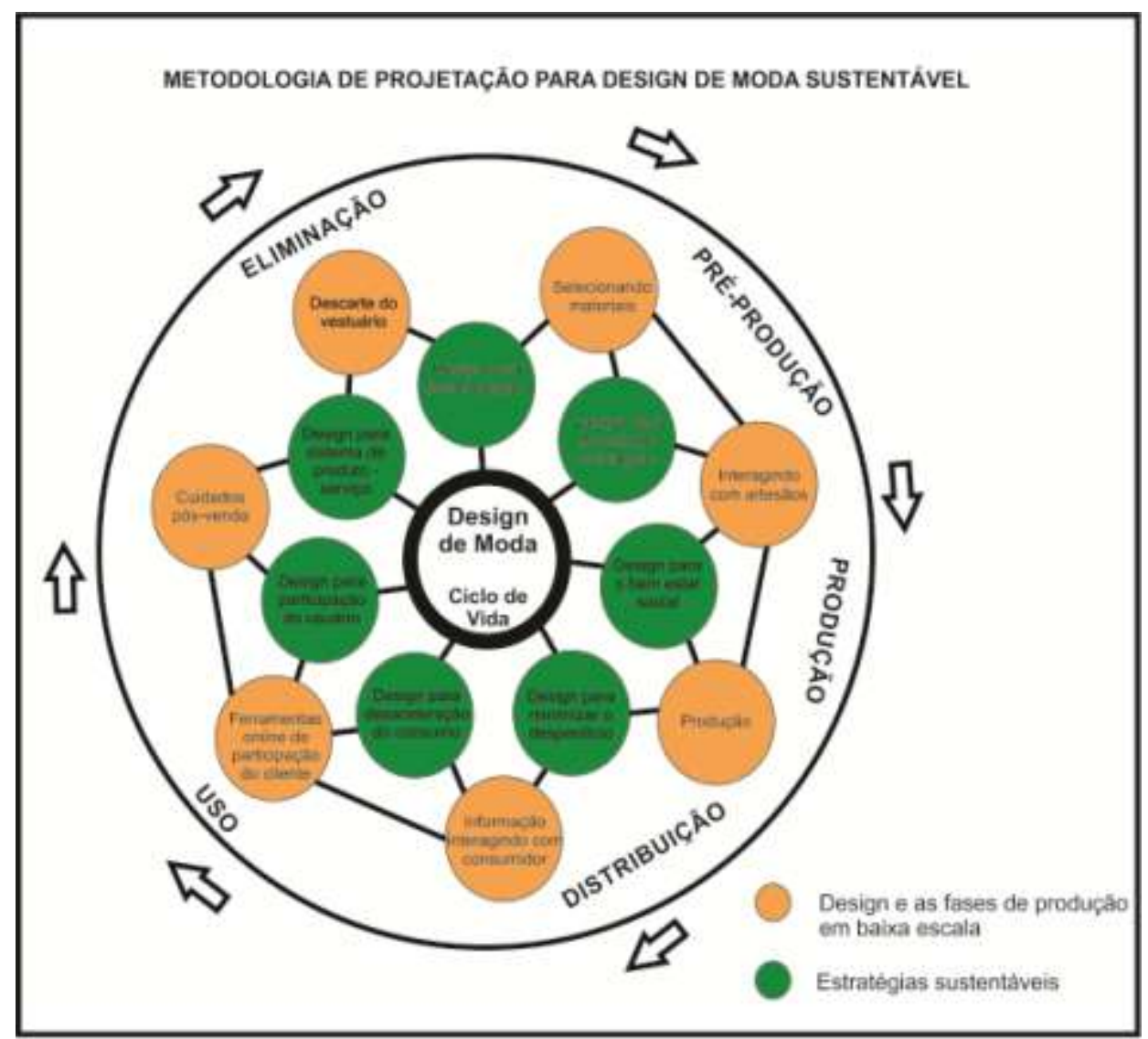

Figura 2: Metodologia de projetação para design de moda sustentável. Fonte: as autoras.

O design para o bem estar social está relacionado com as condições de trabalho dos atores/parceiros envolvidos ao longo do processo, assim como a integração entre os mesmos, de forma a promover a convergência de seus interesses econômicos na redução de recursos e custos, buscando aumento da ecoeficiência.

O design para minimizar o desperdício, também chamado de design para a minimização de resíduos por Gwilt e Rissanen (2011), propõe a redução de desperdício de resíduos ao longo da cadeia produtiva (ex. tecidos e aviamentos em geral). Nesta etapa, a busca pelo zero waste (resíduo zero) é o objetivo principal. O zero waste pode ser alcançado de algumas formas: modelagens com formas geométricas cujos encaixes resultem no aproveitamento total do tecido, modelagens tradicionais cujos resíduos são aproveitados em outros processos de embelezamento (ex. colagens têxteis), ou ainda através de processos de construção de roupa como o wholegarment (malharia retilínea na qual a peça é tecida de forma inteira na máquina) (ANICET \&RUTHSCHILLING, 2013).

No design para a desaceleração do consumo pode-se pensar novas formas de produção, como as alinhadas ao sistema slow fashion, que significa trabalhar no ritmo certo, evitar o estresse e desenvolver peças com características atemporais. Assim evita a obsolescência, garantindo qualidade estética e técnica, o que resulta em maior durabilidade. Em relação ao consumidor, deve ter maior consciência ao adquirir produtos mais duráveis e saber preservá-los, ou seja, mantê-los de forma sustentável (RUTHSCHILLING E SANTOS, 2012). Os processos cotidianos de conservação de roupas 
envolvem especial atenção a lavagem e a passadoria, processos que despendem muita energia e uso de produtos como detergentes e amaciantes que prejudicam o meio ambiente. Cabe se colocar nesse item de manutenção a atenção que se deve ter ao espaço que as roupas ocupam nos guarda-roupas, closets, considerando o tempo de armazenamento, também entendido hoje como uma questão de impacto ambiental.

No design para participação do usuário, deve-se ter um relacionamento direto entre a empresa fabricante da roupa com o usuário a fim de analisar o feedback do cliente e colocar em prática as melhorias. Nesse sentido, já há muitos recursos disponíveis, principalmente os apoiados por redes eletrônicas, sites, redes sociais etc.

Em relação ao design para sistema de produto-serviço, apóia-se na definição de Vezzoli: "design de sistemas de produtos e serviços ecoeficientes, socialmente coesos e equânimes, que sejam capazes de satisfazer a uma demanda específica (de clientes/usuários), bem como o design de interação dos atores envolvidos no sistema de produção de valor" (VEZZOLI, 2010, p.37).

O design para a desmontagem, ainda está a ser estudado na moda de forma a torná-lo mais eficiente, visto que muitas vezes é difícil ou quase impossível separar as partes que compõem o produto para a realização de outro produto. Engloba o projeto de sistemas de componentes e de materiais que ajudam ou diminuem o trabalho e o tempo gasto no processo de separação desses elementos, visando à manutenção ou a reciclagem das partes dos produtos (ANICET, 2012).

E por último o design para fim de vida do produto, que usa processos como upcycling e reciclagem. O upcycling na moda pode ser trabalhado de maneira a reutilizar os resíduos, ressaltar sua beleza, transformando em novos produtos com valor agregado, sem que se tenha a necessidade de despender mais energia em outro processo. Muitas vezes o upcycling é considerado uma ação mais sustentável que a reciclagem por que a reciclagem prevê não só o gasto de energia como as matériasprimas tendem a perderem qualidade na medida em que passam por um novo processo. Por outro lado, em alguns casos os resíduos são tão pequenos que a única solução sustentável é a reciclagem. Um exemplo disto é a reciclagem de restos fios de malharia na construção de novos fios.

“O elemento sustentável, assim, tornar-se uma parte natural da própria produção e não será mais credenciado como uma tendência de curto prazo. Isso também irá colocar pressão sobre os produtores para que a influência também tenha um efeito para o outro lado e pode gradualmente estimular a produção mais respeitadores do ambiente" (JENSEN \& DAHL, 2008, p.149).

\section{CONCLUSÃO}

Conforme os resultados descritos neste artigo, a pesquisa baseada em observação participante e confronto com resultados teóricos encontrados pela pesquisa bibliográfica, pode-se afirmar que o elemento responsável pela mudança na cadeia produtiva de moda com vistas à introdução dos princípios sustentáveis é o designer de micro e pequenas empresas.

Esse profissional possui posição central no processo produtivo e controle sobre todas as etapas, desde o conceito adotado, o processo criativo e todas as fases 
produtivas já descritas anteriormente, passando pela aprovação das peças de mostruário, controle de qualidade, comunicação e marketing. Sendo assim, ele tem poder de influenciar sua equipe, fornecedores, representantes, vendedores, compradores e consumidor na conscientização para sustentabilidade. De dentro da micro e pequena empresa deve surgir a "chama" de mudança que acabará por influenciar todo o mercado da moda. Acredita-se que este processo seja lento, porém constante e eficaz por que vai contar com o marketing, a divulgação dessa tomada de consciência inclusive por parte dos usuários que já estão atentos à causa ecológica e sustentável.

Para atingir esses objetivos, este artigo divulga novos métodos de projetação de design de moda alinhado a estratégias de ciclo de vida, que estão sendo adotados por algumas empresas comprometidas com a sustentabilidade.

As estratégias para criar produtos de moda e vestuário sustentáveis tendem ao infinito e neste artigo foram apresentadas as principais. Por outro lado, não se buscam modelos fechados e perfeitos, uma vez que se projeta para fim em aberto, mas se deve ter sempre o objetivo de minimizar os impactos negativos e maximizar os impactos positivos.

O maior desafio não é projetar roupas sustentáveis, mas encorajar a mudança na sociedade. O cenário ideal é que um dia os designers planejem produtos, serviços e sistemas de forma a garantir o compromisso com a causa sustentável na sociedade.

\section{REFERÊNCIAS}

Referências de Livro:

BLACK, Sandy. Eco-Chic: The Fashion Paradox. Black Dog Publishing: London, 2008.

FLETCHER, Kate. Sustainable Fashion \& Textiles: Design Journeys. London: Earthscan, 2011.

FLETCHER, Kate; GROOSE, Lynda. Moda e sustentabilidade: design para mudança. Tradução Janaína Marcoantonio. São Paulo: Editora SENAC São Paulo, 2011.

FUAD-LUKE, Alastair. The Ecodesign Handbook: a complete sourcebook for the home and office. Thames\&Hudson: London, 2004.

FUAD-LUKE, Alastair. Ecodesign: the sourcebook. São Francisco, CA: Chronicle Books, 2010.

GWILT, Alison. Producing sustainable fashion: The points for Positive Intervention by the Fashion Designer. In: Shaping Sustainable Fashion: changing the way we make and use clothes. London: Earthscan, 2011.

GWILT, Alison; RISSANEN, Timo. Shaping Sustainable Fashion: changing the way we make and use clothes. London: Earthscan, 2011.

JENSEN, Tina Hjort; DAHL, Eva Himmelstrup. Guidelines in Beyond Green: Sustainability and Fashion. Control Union World Group, ArtEZ Press: Arnhem, Netherlands, 2008. 
KAWAMURA, Yuniya. Fashion-ology. Berg: Oxford, New York, 2005.

MANZINI, Ezio; VEZZOLI, Carlo. O desenvolvimento de produtos sustentáveis: os requisitos ambientais dos produtos industriais. São Paulo: EDUSP/ Editora da Universidade de São Paulo, 2008.

PETERSON, Joel; EKWALL, Daniel. Production and business methods in the integral knitting supply chain. AUTEX Research Journal, vol. 8, December, 2007.

RECH, Sandra. Moda: por um fio de qualidade. Florianópolis: UDESC, 2002.

RUTHSCHILLING, Evelise Anicet; SANTOS, Aguinaldo dos. Design para consumo

sustentável de roupas. Anais 1st International Fashion and Design Congress - CIMODE

- Universidade do Minho, Portugal, 2012.

SINHA, P. Creativity in fashion. In: Journal of Textile and Apparel, Technology and Management, vol 2, no 1V, 2002.

SORGER, R.; UDALE, J. Princípios básicos del diseño de moda. Barcelona: G. Gilli, 2008.

TREPTOW, Dóris. Inventando Moda: planejamento de coleção. Brusque: 2003.

VEZZOLI, Carlo. Design e sistema de inovação para a sustentabilidade. In: Moda, Sustentabilidade e Emergências. Org. Ana Mery Sehbe De Carli, Bernadete Lenita Suzin Venzon. Caxias do Sul, RS: EDUCS, 2012.

VEZZOLI, Carlo. Design de sistemas para a sustentabilidade: teoria, métodos e ferramentas para o design sustentável de "sistemas de satisfação". Salvador: EDUFBA, 2010.

Referências de Teses:

ANICET, Anne. Colagens Têxteis: em busca de um design sustentável. Tese de Doutorado em Design. 2012. Universidade de Aveiro, Curso de Pós-graduação em Design.

Meio Eletrônico:

a) Revista eletrônica:

ANICET, Anne, RUTHSCHILLING, Evelise. Contextura: processos produtivos sob abordagem Zero Waste. Modapalavra E-periódico/ Universidade do Estado de Santa Catarina. Centro de Artes / Departamento de Moda, Ano 6, n.12, [no prelo] jan-jul (2013). Florianópolis: UDESC/CEART, 2013. Periodicidade: Semestral. ISSN: 1982 $615 x$

\section{b) Internet}

CARROLL, Lewis. Alice's adventures in wonderland. London: Knowledge Matters, 1999. Disponível na internet por HTTP em: < http://literature.org/authors/carrolllewis>. Acesso em 19 nov. 2002

Cenário Vestuário, SEBRAE, 
http://app.pr.sebrae.com.br/portalsetor/Principal.do?portal=24\&codMenu=512 